\title{
Review \\ Nitric oxide in inflammation and pain associated with osteoarthritis
}

\author{
Steven B Abramson
}

Division of Rheumatology, Hospital for Joint Diseases, New York University School of Medicine, 301 E. 17th Street, New York, NY 10003, USA

Corresponding author: Steven B Abramson, stevenb.abramson@nyumc.org

Published: 17 October 2008

This article is online at http://arthritis-research.com/supplements/10/S2/S2

(c) 2008 BioMed Central Ltd
Arthritis Research \& Therapy 2008, 10(Suppl 2):S2 (doi:10.1186/ar2463)

(TNF)- $\alpha$, and prostaglandins, are all over-produced in chondrocytes harvested from patients with OA (as reviewed by Pelletier and coworkers [1]) and help to perpetuate the inflammatory process. NO has also long been considered to be a catabolic factor that contributes to the OA disease pathology by mediating a number of processes, including apoptosis, and perpetuating the expression of proinflammatory cytokines [1]. High concentrations of nitrites and nitrates have been found in the synovial fluid and plasma of patients with arthritis [2]. Although increased levels of NO activity have been found in the synovial fluid of patients with rheumatoid arthritis [3,4] and juvenile idiopathic arthritis [5], analyses of the NO content in the synovial fluid of patients with $\mathrm{OA}$ have yielded contradictory findings $[6,7]$. NO concentrations are, however, significantly increased in the synovial fluid of a canine OA model [8]. These findings, in combination with experiments described below, contribute to the prevailing hypothesis that $\mathrm{NO}$ is a proinflammatory and proapoptotic factor that, when present in excess, is detrimental to the joint and contributes to OA pathogenesis.

Despite the evidence that $\mathrm{NO}$ is primarily a catabolic factor in $\mathrm{OA}$, newer studies have suggested that this view of NO may be too simplistic. Instead, there is evidence that the effects of NO may be concentration and/or time dependent. In addition, studies suggest that $\mathrm{NO}$ and its reactive oxygen species (ROS) derivatives may also have opposing effects, both destructive and protective. Finally, there is a small but growing body of literature demonstrating that NO has beneficial effects on other cell types, including tendons and osteoblasts, which could also potentially be present in chondrocytes. In addition, NO and its derivatives also play critical roles in both the production and reduction of nociception and pain, which is the primary cause of functional

$\mathrm{CINOD}=$ cyclo-oxygenase inhibiting nitric oxide donating; $\mathrm{COX}=$ cyclo-oxygenase; $\mathrm{IL}=$ interleukin; $\mathrm{NOS}=$ inducible $\mathrm{NOS} ; \mathrm{MPC}=$ mesenchymal progenitor cell; NF-KB = nuclear factor- $\mathrm{KB}$; $\mathrm{NO}=$ nitric oxide; $\mathrm{NOS}=$ nitric oxide synthase; $\mathrm{OA}=$ osteoarthritis; RNOS = reactive nitrogen oxide species; ROS $=$ reactive oxygen species; SIN-1 = 3morpholiosydnonimine; SNP = sodium nitroprusside; SOD $=$ superoxide dismutase; TNF = tumor necrosis factor. 
disability in OA. These studies suggest that NO donors could be an asset in the treatment of OA. This article briefly reviews the literature describing a catabolic role for $\mathrm{NO}$ in cartilage and chondrocytes, and then summarizes existing studies that may suggest alternative roles for $\mathrm{NO}$ in the joint.

\section{Introduction to nitric oxide}

$\mathrm{NO}$ is synthesized in mammalian cells by the conversion of L-arginine to L-citrulline plus NO. This reaction is catalyzed by one of three isoforms of nitric oxide synthase (NOS). Two of the NOS enzymes, namely endothelial NOS and neuronal NOS, are calcium dependent and constitutively produce relatively low levels of NO. The inducible isoform (inducible NOS [iNOS]) is expressed for a longer period of time upon activation by a variety of factors, including the inflammatory cytokines TNF- $\alpha$ and lipopolysaccharide (reviewed by Weinberg and coworkers [9]). Once synthesized, NO can diffuse within the same cell or neighboring cells, where it binds to the heme group of soluble guanylyl cyclase to generate cGMP from GTP [10]. Activated cGMP then binds specifically to target proteins including transcription factors, protein kinases and phosphodiesterases to elicit downstream effects. However, NO can also act in a cGMP-independent manner, for example by directly modifying proteins or contributing to the oxidation of proteins and lipids, further increasing the complexity and number of potential roles for $\mathrm{NO}$ in normal and pathophysiologic functions [11].

In addition to signaling by the NO molecule alone, ROS including superoxide, hydrogen peroxide, and peroxynitrite are also involved in mediating cellular functions. It is clear that these molecules also have specific cellular functions and play specific roles in pathogenesis. Peroxynitrite is generated by the combination of $\mathrm{NO}$ and superoxide, and it contributes to a number of destructive events in cartilage, including apoptosis $[12,13]$. Joint fluid analysis in patients with OA identified significantly lower concentrations of the superoxide scavenger enzyme extracellular superoxide dismutase (SOD), suggesting an increase in oxidative damage may contribute to damage caused by OA [14]. Like NO, however, studies have suggested that the role of reactive nitrogen oxide species (RNOS) in the cell is complex, and newly discovered functions are still being described in the literature.

Although this review focuses primarily on the role played by $\mathrm{NO}$ and its redox derivatives in the pathogenesis of OA, NO is also involved in normal development. For example, experiments in chick growth plate chondrocytes illustrated that all three isoforms of NOS are expressed and active in the growth plate (Figure 1) [15], and we have detected both endothelial NOS and neuronal NOS mRNA in chondrocytes of patients with OA [16]. NO donors increased alkaline phosphatase activity, and transfection of the endothelial NOS isoform increased collagen type $\mathrm{X}$ expression. Conversely, incubation with NOS inhibitors reversed the increase in alkaline phosphatase activity, whereas cGMP inhibitors reversed the increases in alkaline phosphatase activity and collagen expression, demonstrating that $\mathrm{NO}$ helps to mediate the terminal differentiation of chondrocytes. These experiments show that NO helps regulate two steps in chondrocyte development, namely expression of collagen type $\mathrm{X}$ as well as alkaline phosphatase activity [15], illustrating just one example of a nonpathological role for NO.

\section{Catabolic role of nitric oxide in chondrocytes}

As mentioned in the Introduction section (above), there are numerous examples of the catabolic effects of $\mathrm{NO}$ on cultured chondrocytes and cartilage. Chondrocytes from patients with OA express iNOS in the superficial zone [16,17], reflecting an increase in NO during the OA disease process. NO also inhibits the synthesis of both proteoglycans and collagen in rabbit cartilage cultures [18] and has been shown to upregulate the synthesis of matrix metalloproteinases in a cGMP-dependent manner [19,20]; both of these actions contribute to destruction of the extracellular matrix. In addition, $\mathrm{NO}$ mediates the expression of proinflammatory cytokines, including IL-18, and the synthesis of the IL-1-converting enzyme, a caspase required for the maturation of both IL-1 and IL-18 [21]. These findings support the conclusion that NO is primarily a catabolic factor in OA.

However, not all chondrocytes respond identically to proinflammatory stimuli, and neither do all chondrocytes produce equivalent amounts of NO when they are exposed to the same stimulus. This suggests that a straightforward catabolic role for $\mathrm{NO}$ in the joint may be too simplistic. Häuselmann and colleagues [22] harvested chondrocytes from different zones of articular cartilage and observed that different layers of cartilage generated varying amounts of NO in response to IL-1 stimulation. Specifically, chondrocytes from the superficial layer of normal human cartilage synthesized two to three times as much NO as did those from the deep zone of the same cartilage sample. IL-1 stimulation inhibited proteoglycan synthesis equally in both zones. However, in the presence of

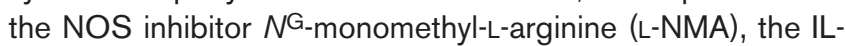
1 -induced inhibition of proteoglycan synthesis was completely reversed in the deep zone whereas only a partial effect was observed in the superficial zone. In addition, exposure to L-NMA and IL-1 together reduced the metabolic half-life of proteoglycans in the deep and superficial zones, despite the differing effects on proteoglycan inhibition. Finally, the authors observed that NO production in response to IL-1 stimulation declined with age. These findings led the authors to suggest that NO may not mediate extracellular matrix turnover identically throughout articular cartilage and, perhaps, plays a protective role in proteoglycan catabolism [22].

Intriguingly, chondrocytes not only respond differently to NO based on their location in the cartilage, but different effects on cartilage can be elicited depending on the method used to inhibit inflammation. Bezerra and coworkers [23] examined the effects of $\mathrm{NO}$ and peroxynitrite in zymosan-induced 


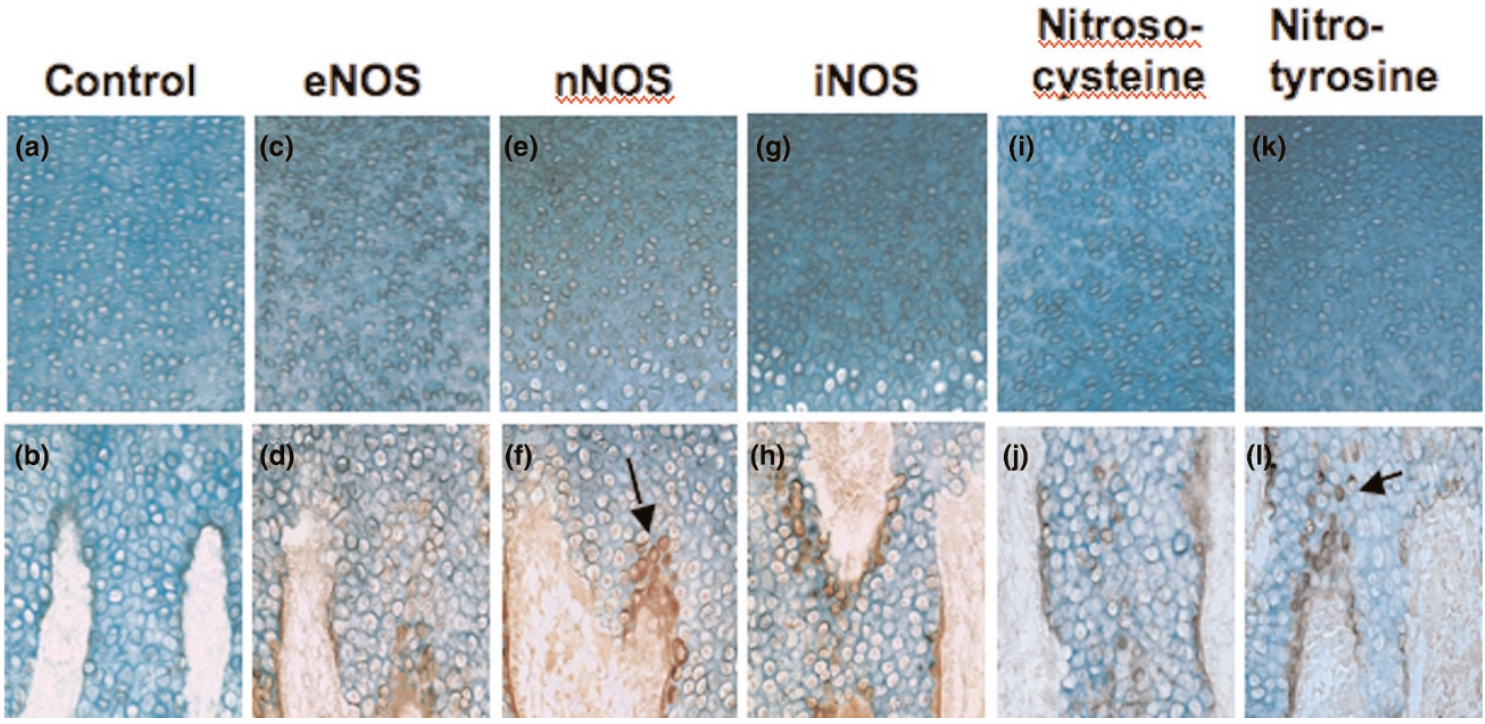

Expression patterns of NOS enzymes in chick growth plate chondrocytes. Longitudinal sections through 8-week-old proximal tibia were immunostained with the antibodies listed and counterstained with Alcian Blue. The upper panels represent the proliferative zone and lower ones the hypertrophic region of the growth plate. $(a, b)$ Control section, $(c, d)$ eNOS, $(e, f)$ nNOS (note that the arrow indicates positively stained hypertrophic chondrocytes), (g,h) iNOS, (i,j) anti-nitrocysteine, (k,l) anti-nitrotyrosine (arrow points to an accumulation of nitrosylated and nitrated products). eNOS, endothelial nitric oxide synthase; iNOS, inducible nitric oxide synthase; nNOS, neuronal nitric oxide synthase. Reproduced with permission from Teixeira and coworkers [15].

arthritis, and found that the addition of both NO and peroxynitrite induced inflammation (as measured by histopathology and the glycosaminoglycan content of the cartilage). Furthermore, when a nonselective NOS inhibitor or a selective iNOS inhibitor was added, the synovitis was improved but the glycosaminoglycan loss was enhanced. This indicates that although blocking NO production helps to decrease inflammation, cartilage damage is enhanced. Finally, when the peroxynitrite scavenger uric acid was added, both the synovitis and glycosaminoglycan loss was ameliorated, suggesting that inhibiting peroxynitrite production may be a more effective target for protecting against inflammation and cartilage loss in this arthritis model [23]. Again, these experiments, combined with the different behavior associated with chondrocyte location in the joint, suggest that the role played by $\mathrm{NO}$ in the joint may be more complicated than previously understood and that more research is needed.

\section{Nitric oxide and apoptosis}

In addition to contributing to the breakdown of the extracellular matrix, NO also mediates apoptosis. Both exogenous and endogenous $\mathrm{NO}$ can induce apoptosis via a mitochondria-dependent mechanism [24,25]. Studies demonstrated that incubation of human articular chondrocytes with the NO donor sodium nitroprusside (SNP) induced events characteristic of apoptosis, including increasing caspase-3 and caspase-7 expression and downregulating Bcl-2 expression [25]. Further examination of the mechanisms by which SNP induces apoptosis illustrated that
SNP induced DNA fragmentation, cytoskeletal remodeling, mitochondrial dysfunction, caspase activation, and cytochrome c release [26], all of which are hallmarks of apoptosis. Treatment with a NO scavenger significantly decreased multiple aspects of SNP-induced cell damage [26], once again demonstrating the pleiotropic effects of NO.

Interestingly, del Carlo and Loeser [12] found that incubation with NO alone does not induce apoptotic cell death in chondrocytes. In these experiments, incubation of chondrocytes with the NO donors SNP and 3-morpholiosydnonimine (SIN-1), as well as the ROS peroxynitrite, all induced apoptosis. However, both SNP and SIN-1 also generate ROS and are not considered to be sources of pure NO. Specifically, SIN-1 generates superoxide in addition to NO $[27,28]$, which can then interact with $\mathrm{NO}$ to generate peroxynitrite. In support of this, treatment with either peroxynitrite or superoxide scavengers resulted in protection against apoptosis caused by incubation with $\mathrm{SIN}-1$ but not with SNP. Intriguingly, incubation with diazeniumdiolates (NOC compounds), which are reliable sources of NO, did not cause cell death and the NOC compounds protected against oxidative stress, perhaps by suppressing chondrocyte energy metabolism. This study demonstrated that both NO and ROS are required to induce apoptosis, suggesting that $\mathrm{NO}$ alone may have beneficial effects in chondrocytes [12].

Other studies on the effect of NO on chondrocyte apoptosis have focused on the role of apoptosis in terminal differen- 
tiation, again illustrating a nonpathological role for $\mathrm{NO}$ in development. An increase in inorganic phosphate was shown to induce apoptosis in terminally differentiated epiphyseal chondrocytes [29]. Subsequent studies demonstrated that inorganic phosphate increased both nitrate and nitrite concentrations, and this increase was attenuated when either NOS activity or phosphate transport was inhibited. In addition, inorganic phosphate increased caspase-3 activity and decreased the mitochondrial membrane potential, whereas NOS inhibitors maintained mitochondrial function, illustrating that NO mediates phosphate-dependent chondrocyte apoptosis [29].

\section{Effects of reactive oxygen and nitrogen species on chondrocytes and other cell types}

ROS have been shown to have deleterious effects on cells and to contribute to chondrocyte death. Davies and colleagues [30] demonstrated that $\mathrm{OA}$ cartilage has significantly more DNA damage than normal cartilage, and that this damage was mediated by IL-1 and, ultimately, by ROS. Porcine articular cartilage was harvested from normal tissue and compared with cartilage harvested from OA tissue and the number of single-stranded and double-stranded DNA breaks was analyzed. In cells from healthy cartilage, increasing concentrations of IL-1 correlated with increasing $\mathrm{NO}$ concentrations and increasing DNA damage. The increase in DNA damage was attenuated by incubation with the specific iNOS inhibitor 1400W and the superoxide scavenger SOD, suggesting that superoxide may have a role in generating DNA breaks. It is not clear, however, what effect DNA damage has on $\mathrm{OA}$ cells and the disease process. The authors suggested that DNA damage could alter transcription by increasing errors, which could result in dysfunctional proteins, or alternatively by inhibiting the binding of transcription factors to promoter regions [30].

There is some evidence that the degenerative activity attributed to an increase in NO concentration could be a result of an increase in the concentration of RNOS. Clancy and coworkers [31] demonstrated that $\mathrm{NO}$ and peroxynitrite have opposing effects on nuclear factor- $\kappa \mathrm{B} \quad(\mathrm{NF}-\kappa \mathrm{B})$ activation in chondrocyte cultures. The transcription factor $\mathrm{NF}-\kappa \mathrm{B}$ is activated rapidly in response to inflammatory stimuli such as IL-1 $\beta$ and TNF- $\alpha$ and upregulates the transcription of a number of genes involved in cartilage degradation including iNOS, matrix metalloproteinases and COX-2, as well as IL-1 $\beta$ and TNF- $\alpha$. Inactive NF- $\kappa B$ is sequestered in the cytoplasm by its inhibitor $I \kappa B$. Upon activation, $I \kappa B$ is phosphorylated and degraded, which allows NF-KB to translocate to the nucleus and bind to its target DNA sequences. When bovine chondrocytes were incubated with IL-1 $\beta, 40 \%$ of the cells had active NF- $\kappa B$, as visualized by positive immunostaining for a NF- $\kappa B$ subunit in the nucleus (Figure 2). When cells were treated with IL-1 $\beta$ and the NO donor $S$-nitrosocysteine ethyl ester, the number of cells with nuclear NF- $\kappa B$ decreased to $5 \%$. However, incubation with IL-1 $\beta$ and peroxynitrite resulted in an increase in cells with activated NF- $\kappa \mathrm{B}$ from $40 \%$ to $73 \%$, illustrating opposing effects of NO and ROS (Figure 2). These experiments suggest that $\mathrm{NO}$ is not required for immediate activation of NF- $\mathrm{KB}$ and suggest that its catabolic activity could be mediated in part through peroxynitrite [31].

Another group analyzed the differential roles of hydrogen peroxide and superoxide in IL-1-induced NF- $\kappa B$ activation. Mendes and colleagues [32] found that IL-1 stimulation resulted in an increase in both hydrogen peroxide and superoxide in bovine articular chondrocytes, although only superoxide was required for NF-KB activation and iNOS expression. This conclusion is supported by the fact that SOD inhibited IL-1-induced I $\mathrm{B} B$ degradation. Like Clancy and coworkers [31], this group also found that $\mathrm{NO}$ alone inhibits NF- $\kappa B$ activation and iNOS expression [33], but they suggested that because the concentration of $\mathrm{NO}$ immediately after IL-1 stimulation appeared to be quite low, it was unlikely that significant quantities of peroxynitrite were generated. This led them to suggest that peroxynitrite is not likely to be required for NF- $\mathrm{KB}$ activation in chondrocytes. However, these results do not exclude the possibility that peroxynitrite is able to activate NF- $\kappa \mathrm{B}$, merely that it may not be required. These results clearly demonstrate the difficulty in teasing out the specific roles played by both $\mathrm{NO}$ and ROS in order to determine their involvement in IL-1-induced NF- $\mathrm{KB}$ activation.

Peroxynitrite also helps perpetuate the inflammatory process in mesenchymal progenitor cells (MPCs), which are used as a model of cartilage and cartilage repair cells. Whiteman and coworkers [34] used MPCs to investigate the cellular role of peroxynitrite-modified collagen-II, a biomarker discovered in the serum of patients with both OA and rheumatoid arthritis. The authors showed that the addition of peroxynitritemodified collagen-II to MPC cultures induced both iNOS expression and cyclo-oxygenase (COX)-2 synthesis and that specific iNOS and COX-2 inhibitors blocked this synthesis. Furthermore, the investigators demonstrated that this upregulation was caused by the activation of NF- $\kappa B$ via mitogen-activated protein kinase signaling through p38 and ERK1/2. Whiteman and coworkers [34] suggest that this newly identified proinflammatory pathway may be a target for the development of new therapies for the inflamed joint, reiterating the complexity of $\mathrm{NO}$ signaling and the need for continuing research to more fully elucidate the role of $\mathrm{NO}$ and its derivatives in cellular physiology and pathophysiology.

\section{Role of nitric oxide in other cell types in the joint}

Although there is experimental evidence to suggest a catabolic function for $\mathrm{NO}$ in the joint, there is also evidence that $\mathrm{NO}$ and its derivatives may play a protective role in chondrocytes. In addition, NO has beneficial functions in other tissues, and these activities could potentially occur in chondrocytes as well. 

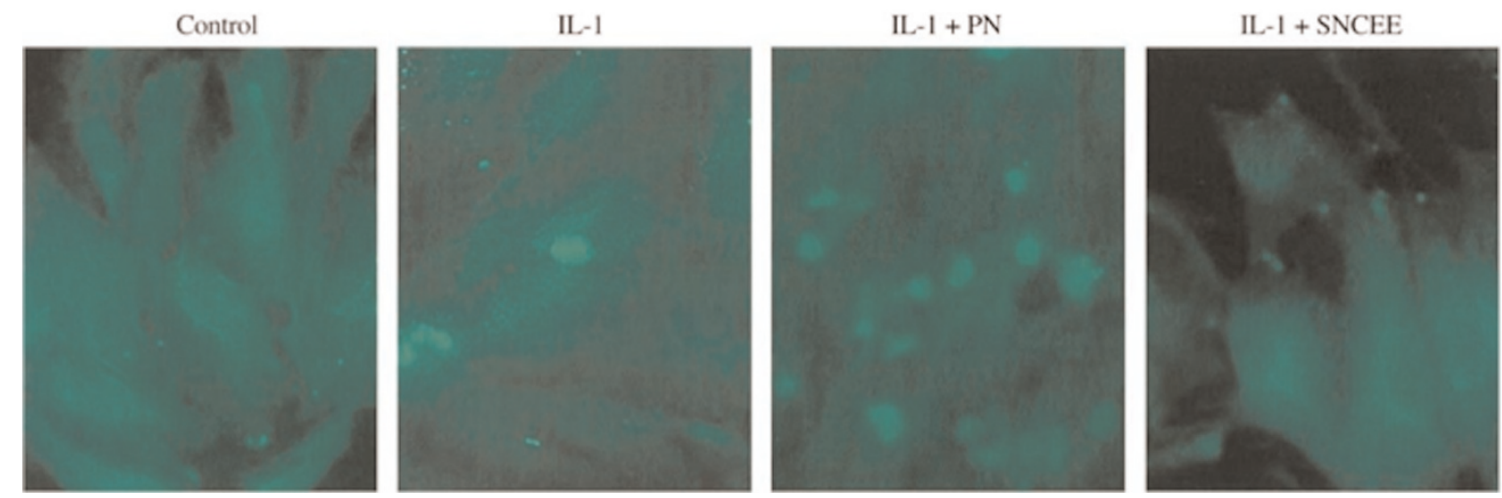

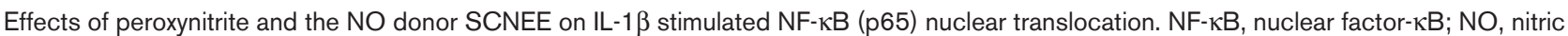
oxide; PN, peroxynitrite; SCNEE, S-nitrosocysteine ethyl ester. Reproduced with permission from Clancy and coworkers [31].

Wound healing experiments showed that supplemental L-arginine injected into animals with dorsal wounds significantly increased both wound-breaking strength and collagen deposition compared with animals injected with saline, although there was no change in plasma NO concentration [35]. NO was also shown to enhance collagen synthesis in human tendon cells in vitro. When cells harvested from the torn edges of tendons from patients undergoing rotating cuff surgery were transfected with an adenovirus containing the gene for iNOS (Ad-iNOS) or treated with the NO donor S-nitroso- $N$-acetylpenicillamine (SNAP), total protein and collagen synthesis was enhanced, although higher doses did inhibit collagen synthesis [36]. These findings were supported by a small randomized double-blind clinical trial in which the same group found that application of a patch containing the NO donor glyceryl trinitrate significantly improved outcomes in patients with supraspinatus tendonopathy compared with patients who received placebo [37]. This illustrates that the benefits of exogenous $\mathrm{NO}$ in tendons is not simply an in vitro effect.

Muscará and colleagues [38] also demonstrated that exogenous $\mathrm{NO}$ is beneficial in a rat wound healing model. The investigators compared the effects of the cyclooxygenase-inhibiting nitric oxide donating (CINOD) agent naproxcinod to its parent compound naproxen on wound healing. Despite inhibiting prostaglandin synthesis to the same extent as naproxen, naproxcinod significantly enhanced collagen deposition at the wound site whereas naproxen decreased collagen deposition, illustrating once again that exogenous NO may help to increase collagen deposition under some conditions. These studies suggest that perhaps there are some conditions in which NO donors could induce collagen deposition in chondrocytes.

Studies have also suggested that exposure to low levels of $\mathrm{NO}$ could be protective against subsequent oxidative stress. Tai and coworkers [39] demonstrated that NO helps to regulate osteoblast activity. Pretreatment of cultured osteoblasts with a low concentration of the NO donor SNP $(0.3 \mathrm{mmol} / \mathrm{l})$ resulted in no change in cell viability and only a slight increase in cellular NO concentration. Treatment with a high concentration of the NO donor SNP ( $2 \mathrm{mmol} / \mathrm{l})$ induced cellular NO and ROS and as well as cell death via apoptosis. However, when osteoblasts were pretreated with the low concentration of SNP and then subjected to the high concentration, cell viability was significantly increased and apoptosis was significantly decreased compared with no pretreatment. This protection was probably mediated via JNKc-Jun-mediated regulation of Bcl-2 gene expression and translocation to the mitochondria. Interestingly, pretreatment with low concentrations of SNP enhanced the increases in both $\mathrm{NO}$ and ROS, demonstrating that the pretreatment is not merely suppressing cellular oxidative stress but in some way protecting against damage. These experiments again illustrate the complexity of the role played by $\mathrm{NO}$ in cellular metabolism as well as the varied responses to ROS in different cell types.

\section{Role of nitric oxide in nociception and pain}

As mentioned above, pain is the major determinant in functional disability caused by OA [40]. NO and RNOS are both involved in perception and reduction of pain, and therefore could be a target for the management of pain in OA. Hancock and Riegger-Krugh [41] recently reviewed several potential mechanisms that may explain the role played by NO in pain reduction in patients with OA: the blood-flow pathway is normalized in the presence of NO, which may help to decrease ischemic pain; the nerve transmission pathway, which decreases the irritation of the nerves in the synovium, bone, and soft tissues; the opioid receptor pathway, which might stimulate the body's normal pain reduction pathways; and the anti-inflammation pathway. The authors concluded that small amounts of transiently produced NO, perhaps produced by endothelial NOS, could potentially decrease the pain associated with $\mathrm{OA}$. However, like the role of $\mathrm{NO}$ in the 
OA disease process, research in this field is still ongoing and there are many outstanding questions.

In addition to NO, RNOS also plays a role in pain and nociception. Wang and coworkers [42] showed that superoxide is involved in pain deriving from inflammation. Injection of a SOD mimetic (M40403) blocked the inflammation, edema, and hyperalgesia associated with carrageenan injection. In addition, the formation of peroxynitrite was also inhibited after injection of M40403, suggesting that both superoxide and peroxynitrite play a role in the development of inflammation and pain. Subsequent experiments by the same laboratory showed that the development of morphine-induced tolerance is associated with increased proinflammatory cytokine production as well as oxidative DNA damage [43]. Inhibition of NO synthesis or the scavenging of superoxide both block the development of morphine-induced tolerance, suggesting that peroxynitrite is involved. This hypothesis was confirmed using a peroxynitrite-decomposition catalyst, which blocked the antinociceptive tolerance response, suggesting once again that decreasing the production of peroxynitrite could help to ameliorate chronic pain.

Peroxynitrite appears to perpetuate the inflammatory process at least in part by helping to induce COX-2 activity. When superoxide or peroxynitrite was injected into rats, the animals developed thermal hyperalgesia, which is associated with tissue damage and inflammation. The response was blocked by the addition of the NOS inhibitor $N G_{\text {-nitro-L-arginine methyl }}$ ester (L-NAME), or a peroxynitrite-decomposition catalyst, suggesting that peroxynitrite was responsible for the effect [44]. Further experiments demonstrated that this led to the activation of NF- $\mathrm{KB}$, which enhanced the expression of the COX-2 but not the COX-1 enzyme. The response was blocked in a dose-dependent manner by the nonselective COX inhibitor indomethacin, the selective COX-2 inhibitor NS398, and an anti-prostaglandin $E_{2}$ antibody. These results confirm that peroxynitrite does mediate hyperalgesia associated with inflammation through the COX-prostaglandin $E_{2}$ pathway.

\section{Conclusion}

The role played by $\mathrm{NO}$ in the function of normal and pathological joints is still incompletely understood. Although it is clear that NO and RNOS both play a role in the OA disease process, as well as in the perception of pain, studies analyzing the effects of NO-donating agents in both chondrocytes and other cell types are providing insights that suggest that there are also protective functions for $\mathrm{NO}$ and its redox derivatives in individual cell types. Future research into the role played by $\mathrm{NO}$ in $\mathrm{OA}$ and the utility of $\mathrm{NO}$ donating agents may provide a new therapeutic option for the treatment of OA with an improved risk profile compared with currently available therapies.

\section{Competing interests}

SBA has consulted for Pfizer, Novartis and NicOx.

\section{Acknowledgments}

The author would like to thank Nina Leeds for editorial and referencing assistance with this manuscript.

This article is published as part of Arthritis Research \& Therapy Volume 10 Supplement 2, 2008: New insights in the role of nitric oxide in the management of osteoarthritis. The full contents of the supplement are available online at http://arthritis-research.com/supplements/10/S2.

Publication of the supplement has been supported by an unrestricted educational grant from NicOx.

\section{References}

1. Pelletier JP, Martel-Pelletier J, Abramson SB: Osteoarthritis, an inflammatory disease: potential implication for the selection of new therapeutic targets. Arthritis Rheum 2001, 44:1237-1247.

2. Farrell AJ, Blake DR, Palmer RM, Moncada S: Increased concentrations of nitrite in synovial fluid and serum samples suggest increased nitric oxide synthesis in rheumatic diseases. Ann Rheum Dis 1992, 51:1219-1222.

3. Maki-Petaja KM, Cheriyan J, Booth AD, Hall FC, Brown J, Wallace $\mathrm{SM}$, Ashby MJ, McEniery CM, Wilkinson IB: Inducible nitric oxide synthase activity is increased in patients with rheumatoid arthritis and contributes to endothelial dysfunction. Int $J$ Cardiol 2008 [Epub ahead of print].

4. Migita K, Yamasaki S, Ida H, Kita M, Hida A, Shibatomi K, Kawakami A, Aoyagi T, Eguchi K: The role of peroxynitrite in cyclooxygenase-2 expression of rheumatoid synovium. Clin Exp Rheumatol 2002, 20:59-62.

5. Lotito AP, Muscara MN, Kiss MH, Teixeira SA, Novaes GS, Laurindo IM, Silva CA, Mello SB: Nitric oxide-derived species in synovial fluid from patients with juvenile idiopathic arthritis. $J$ Rheumatol 2004, 31:992-997.

6. Haklar U, Yuksel M, Velioglu A, Turkmen M, Haklar G, Yalcin AS: Oxygen radicals and nitric oxide levels in chondral or meniscal lesions or both. Clin Orthop Relat Res 2002, 403:135-142.

7. Karan A, Karan MA, Vural P, Erten N, Tascioglu C, Aksoy C, Canbaz M, Oncel A: Synovial fluid nitric oxide levels in patients with knee osteoarthritis. Clin Rheumatol 2003, 22:397-399.

8. Spreng D, Sigrist N, Schweighauser A, Busato A, Schawalder P: Endogenous nitric oxide production in canine osteoarthritis: detection in urine, serum, and synovial fluid specimens. Vet Surg 2001, 30:191-199.

9. Weinberg JB, Fermor B, Guilak F: Nitric oxide synthase and cyclooxygenase interactions in cartilage and meniscus: relationships to joint physiology, arthritis, and tissue repair. Subcell Biochem 2007, 42:31-62.

10. Murad F: Shattuck Lecture. Nitric oxide and cyclic GMP in cell signaling and drug development. $N$ Engl J Med 2006, 355: 2003-2011.

11. Stamler JS, Lamas S, Fang FC: Nitrosylation. the prototypic redox-based signaling mechanism. Cell 2001, 106:675-683.

12. Del Carlo M Jr, Loeser RF: Nitric oxide-mediated chondrocyte cell death requires the generation of additional reactive oxygen species. Arthritis Rheum 2002, 46:394-403.

13. Pacher $P$, Beckman JS, Liaudet L: Nitric oxide and peroxynitrite in health and disease. Physiol Rev 2007, 87:315-424.

14. Regan EA, Bowler RP, Crapo JD: Joint fluid antioxidants are decreased in osteoarthritic joints compared to joints with macroscopically intact cartilage and subacute injury. Osteoarthritis Cartilage 2008, 16:515-521.

15. Teixeira CC, Ischiropoulos H, Leboy PS, Adams SL, Shapiro IM: Nitric oxide-nitric oxide synthase regulates key maturational events during chondrocyte terminal differentiation. Bone 2005, 37:37-45.

16. Amin AR, Di Cesare PE, Vyas P, Attur M, Tzeng E, Billiar TR, Stuchin SA, Abramson SB: The expression and regulation of nitric oxide synthase in human osteoarthritis-affected chondrocytes: evidence for up-regulated neuronal nitric oxide synthase. J Exp Med 1995, 182:2097-2102.

17. Melchiorri C, Meliconi R, Frizziero L, Silvestri T, Pulsatelli L, Mazzetti I, Borzi RM, Uguccioni M, Facchini A: Enhanced and coordinated in vivo expression of inflammatory cytokines and nitric oxide synthase by chondrocytes from patients with osteoarthritis. Arthritis Rheum 1998, 41:2165-2174. 
18. Taskiran D, Stefanovic-Racic M, Georgescu H, Evans C: Nitric oxide mediates suppression of cartilage proteoglycan synthesis by interleukin-1. Biochem Biophys Res Commun 1994, 200: 142-148.

19. Ridnour LA, Windhausen AN, Isenberg JS, Yeung N, Thomas DD, Vitek MP, Roberts DD, Wink DA: Nitric oxide regulates matrix metalloproteinase-9 activity by guanylyl-cyclase-dependent and -independent pathways. Proc Natl Acad Sci USA 2007, 104:16898-16903.

20. Sasaki K, Hattori T, Fujisawa T, Takahashi K, Inoue H, Takigawa M: Nitric oxide mediates interleukin-1-induced gene expression of matrix metalloproteinases and basic fibroblast growth factor in cultured rabbit articular chondrocytes. I Biochem 1998, 123:431-439.

21. Boileau C, Martel-Pelletier J, Moldovan F, Jouzeau JY, Netter P, Manning PT, Pelletier JP: The in situ up-regulation of chondrocyte interleukin-1-converting enzyme and interleukin-18 levels in experimental osteoarthritis is mediated by nitric oxide. Arthritis Rheum 2002, 46:2637-2647.

22. Hauselmann HJ, Stefanovic-Racic M, Michel BA, Evans CH: Differences in nitric oxide production by superficial and deep human articular chondrocytes: implications for proteoglycan turnover in inflammatory joint diseases. J Immunol 1998, 160: 1444-1448.

23. Bezerra MM, Brain SD, Greenacre S, Jeronimo SM, de Melo LB, Keeble J, da Rocha FA: Reactive nitrogen species scavenging, rather than nitric oxide inhibition, protects from articular cartilage damage in rat zymosan-induced arthritis. $\mathrm{Br} J$ Pharmacol 2004, 141:172-182.

24. Wu GJ, Chen TG, Chang HC, Chiu WT, Chang CC, Chen RM: Nitric oxide from both exogenous and endogenous sources activates mitochondria-dependent events and induces insults to human chondrocytes. J Cell Biochem 2007, 101:1520-1531.

25. Maneiro E, Lopez-Armada MJ, de Andres MC, Carames B, Martin MA, Bonilla A, Del Hoyo P, Galdo F, Arenas J, Blanco FJ: Effect of nitric oxide on mitochondrial respiratory activity of human articular chondrocytes. Ann Rheum Dis 2005, 64:388-395.

26. Cherng YG, Chang HC, Lin YL, Kuo ML, Chiu WT, Chen RM: Apoptotic insults to human chondrocytes induced by sodium nitroprusside are involved in sequential events, including cytoskeletal remodeling, phosphorylation of mitogen-activated protein kinase kinase kinase-1/c-Jun $\mathrm{N}$-terminal kinase, and Bax-mitochondria-mediated caspase activation. J Orthop Res 2008, 26:1018-1026.

27. Feelisch $M$, Ostrowski J, Noack E: On the mechanism of NO release from sydnonimines. J Cardiovasc Pharmacol 1989, 14 (suppl 11):S13-S22.

28. Huie RE, Padmaja S: The reaction of no with superoxide. Free Radic Res Commun 1993, 18:195-199.

29. Mansfield K, Rajpurohit R, Shapiro IM: Extracellular phosphate ions cause apoptosis of terminally differentiated epiphyseal chondrocytes. J Cell Physiol 1999, 179:276-286.

30. Davies CM, Guilak F, Weinberg JB, Fermor B: Reactive nitrogen and oxygen species in interleukin-1-mediated DNA damage associated with osteoarthritis. Osteoarthritis Cartilage 2008, 16:624-630.

31. Clancy RM, Gomez PF, Abramson SB: Nitric oxide sustains nuclear factor kappaB activation in cytokine-stimulated chondrocytes. Osteoarthritis Cartilage 2004, 12:552-558.

32. Mendes AF, Caramona MM, Carvalho AP, Lopes MC: Differential roles of hydrogen peroxide and superoxide in mediating IL-1induced NF-kappa B activation and iNOS expression in bovine articular chondrocytes. J Cell Biochem 2003, 88:783-793.

33. Mendes AF, Carvalho AP, Caramona MM, Lopes MC: Role of nitric oxide in the activation of NF-kappaB, AP-1 and NOS II expression in articular chondrocytes. Inflamm Res 2002, 51:369-375.

34. Whiteman M, Spencer JP, Zhu YZ, Armstrong JS, Schantz JT: Peroxynitrite-modified collagen-II induces p38/ERK and NFkappaB-dependent synthesis of prostaglandin E2 and nitric oxide in chondrogenically differentiated mesenchymal progenitor cells. Osteoarthritis Cartilage 2006, 14:460-470.

35. Shi HP, Wang SM, Zhang GX, Zhang YJ, Barbul A: Supplemental L-arginine enhances wound healing following trauma/ hemorrhagic shock. Wound Repair Regen 2007, 15:66-70.

36. Xia W, Szomor Z, Wang Y, Murrell GA: Nitric oxide enhances collagen synthesis in cultured human tendon cells. $J$ Orthop Res 2006, 24:159-172.
37. Paoloni JA, Appleyard RC, Nelson J, Murrell GA: Topical glyceryl trinitrate application in the treatment of chronic supraspinatus tendinopathy: a randomized, double-blinded, placebo-controlled clinical trial. Am J Sports Med 2005, 33:806-813.

38. Muscara MN, McKnight W, Asfaha S, Wallace JL: Wound collagen deposition in rats: effects of an NO-NSAID and a selective COX-2 inhibitor. Br J Pharmacol 2000, 129:681-686.

39. Tai YT, Cherng YG, Chang CC, Hwang YP, Chen JT, Chen RM: Pretreatment with low nitric oxide protects osteoblasts from high nitric oxide-induced apoptotic insults through regulation of c-Jun N-terminal kinase/c-Jun-mediated $\mathrm{Bcl}-2$ gene expression and protein translocation. J Orthop Res 2007, 25: 625-635.

40. McAlindon TE, Cooper C, Kirwan JR, Dieppe PA: Determinants of disability in osteoarthritis of the knee. Ann Rheum Dis 1993, 52:258-262.

41. Hancock CM, Riegger-Krugh C: Modulation of pain in osteoarthritis: the role of nitric oxide. Clin J Pain 2008, 24:353-365

42. Wang ZQ, Porreca F, Cuzzocrea S, Galen K, Lightfoot R, Masini E, Muscoli C, Mollace V, Ndengele M, Ischiropoulos H, Salvemini $D$ : A newly identified role for superoxide in inflammatory pain. J Pharmacol Exp Ther 2004, 309:869-878.

43. Muscoli C, Cuzzocrea S, Ndengele MM, Mollace V, Porreca F, Fabrizi F, Esposito E, Masini E, Matuschak GM, Salvemini D: Therapeutic manipulation of peroxynitrite attenuates the development of opiate-induced antinociceptive tolerance in mice. J Clin Invest 2007, 117:3530-3539.

44. Ndengele MM, Cuzzocrea S, Esposito E, Mazzon E, Di Paola R, Matuschak GM, Salvemini D: Cyclooxygenases 1 and 2 contribute to peroxynitrite-mediated inflammatory pain hypersensitivity. FASEB J 2008 [Epub ahead of print]. 